\title{
Some Problems with the Russellian Open Future
}

\author{
Jacek Wawer ${ }^{1}[$
}

Received: 5 January 2018 / Accepted: 23 March 2018 / Published online: 17 May 2018

(C) The Author(s) 2018

\begin{abstract}
In a recently published paper, Todd (Mind, 125(499), pp. 775-798, 2016a) advocates a novel treatment of future contingents. On his view, all statements concerning the contingent future are false. He motivates his semantic postulates by considerations in philosophy of time and modality, in particular by the claim that there is no actual future. I present a number of highly controversial consequences of Todd's theory. Inadequacy of his semantics might indirectly serve as an argument against the philosophical view underpinning his proposal.
\end{abstract}

Keywords Future contingents · Open future $\cdot$ Future tense

Todd (2016a) undertakes a very ambitious project in his recent paper. He tries to motivate a novel treatment of future contingents which would render them all false. He offers a surprisingly simple rationale for his semantic endeavor: a sentence in future tense is true, if and only if what it says happens in the actual future. But if there is no actual future, then nothing happens in the actual future and any sentence in future tense is false. It certainly is an original semantic proposal, well-grounded in existing philosophical views. I am going to argue, however, that it ultimately fails. Upon closer examination, it turns out that Todd's definitions generate numerous difficulties which are hard to accept (or overcome). In my opinion, it indicates that the claim that there is no actual future requires clarification since, when taken at face value, it might lead to unwelcome consequences.

Jacek Wawer

jacek.wawer@fulbrightmail.org

1 Department of Philosophy, Jagiellonian University, ul. Grodzka 52, 31-044 Kraków, Poland 
I shall proceed as follows: firstly, I briefly mention the philosophical considerations that motivate Todd's semantic account. Then, I introduce the first of Todd's semantics (which I call "extremism", for reasons that will soon become apparent) and argue that it is not a plausible account of the future tense. Later, I discuss a milder, "austere" version of the semantics which Todd ultimately recommends. I intend to show that, as far as semantics of "will" is concerned, austerity is hardly better than extremism. Finally, I argue that the austere semantics can be reduced to Peircean semantics of Arthur Prior and explain why it is bad news for Todd.

\section{Metaphysical Background}

Let me first briefly quote the metaphysical views that influence Todd's semantic decisions. The future, following the author's argument, is contingent, if and only if it is not causally determined. Todd prefers to describe the contingent, undetermined future as the "open future." Then, he imposes a very specific condition:

(OF) If the future is open, then there is no actual future.

The author does not motivate the condition, only stipulates it as the starting point of his investigations. Admittedly, the view that there is no actual future is sometimes promoted both in philosophy of time (e.g., by some presentists, like Markosian (2004) or growing blockers, like Tooley (1997)) and in philosophy of possibility (by certain advocates of the branching model of possibilities, like Belnap et al. (2001)). However, it should be underlined that this rendering of openness is rather controversial. For once, it is exclusive. There is a long line of philosophers and theologians who claimed, or can be interpreted to have claimed, that even if there are many possible futures (in this sense, the future is "open"), we can still reasonably assume that only one of these possible futures is (or rather will be) actual. For example, Peter Abelard finds inspiration for such a view in Aristotle's famous De Interpretatione. ${ }^{1}$ A similar view was supported by William of Ockham and Gottfried Wilhelm Leibniz (for references and detailed discussion cf. Øhrstrøm and Hasle 1995, esp. sec. 1.1 and 1.9). In the last century, such a view was defended, by, e.g., Leśniewski (1992), Rescher (1968), Øhrstrøm (1984), or Lewis (1986). In my opinion, it is slightly too hasty on behalf of Todd to qualify all these thinkers, often against their will, as opponents of the "open" future.

Moreover, under one natural understating of the claim that there is no actual future, it says that nothing will actually happen - that is, that all the world's days are run. But then, (OF) would allow us to infer that the world has just come to its end from the assumption that the future is open. It is surely not a valid inference, so (OF) must be wrong (an argument along this line has been presented by Lewis 1986, p. 207).

\footnotetext{
${ }^{1}$ Ironically, Todd takes Aristotle to be the archetype open-futurist who excludes the notion of the actual future. Anyhow, Aristotle can be hardly summoned as a source of authority in this context. The debate over the correct interpretation of the famous passage of De Interpretatione continues for over two millennia and there is little chance that it shall conclusively end any time in the future.
} 
I should stress that Patrick Todd does not fully embrace (OF) in the paper I discuss. At some point, he even admits that " $[\mathrm{t}]$ he motivation for having an open future view may be dubious" (p. 778). He just stipulates (OF) and proceeds to construct a hypothetical argument: If one wished to accept such a notion of the open future, then one could, or even should, accept the semantic proposals he puts forward. Therefore, I will assume, for the purposes of this paper, such a notion of the open future and use it to reconstruct Todd's line of reasoning.

\section{Extremism}

Let me begin with Todd's initial, ingenious proposal (I will refer to it as F1). Following the author, I shall analyze future tense as a propositional operator $(F){ }^{2}$

1. $F \phi$ is true iff (if and only if).

2. The actual future features $\phi$ iff.

3. There is a unique actual future and it features $\phi$.

If the future is open and (OF) is true, then there is no actual future. Then, 3 is untrue, since the first conjunct is not true. Thus, every sentence in future tense is untrue. Since Todd desires to preserve bivalence, he concludes that every sentence of the form $F \phi$ should be considered false:

On the relevant semantics for 'will', something 'will' happen (as a first approximation) if and only if 'the unique actual future' features the thing happening. But if there is no 'unique actual future', as open futurists contend, then (on a Russellian analysis) such a proposition simply comes out false. Todd (2016a, p. 776)

Let me note that the future might well be open, in Todd's sense of the term, even if some truths are settled. For the future to be open, it is sufficient that some issues are unsettled and Aristotle once sanely noticed that "it is necessary that he who lives shall one day die (...) But whether he dies by disease or by violence, is not yet determined." (Metaphysics 1027b, 10-14). Thus, if the world is not determined in every respect, then the future is open, and therefore it does not exist. ${ }^{3}$ Hence, if the future is open, Todd's claim extends to settled truths. It is settled that I will die, but the proposition asserting that I will die is false according to (F1). The result of all sentences in the future tense being false might look unappealing at first, but Todd argues-in the Puritan spirit-that if it is where our philosophical precepts take us, we can do nothing but follow:

On my view, when we try to talk about 'what will happen', we presuppose a metaphysical picture of time and the world that philosophical reflection ultimately recommends that we reject'. Todd (2016a, p. 796).

\footnotetext{
${ }^{2}$ It is a matter of some controversy, whether operators provide the most fortunate formal account of tense (cf. e.g. King 2003).

${ }^{3}$ One might be inclined to say that the 'determined parts' of the future already exist. The insight is later incorporated into Todd's theory. I discuss this modification in the following section.
} 
Todd describes his project as a "Russellian" approach to future contingents and he contrasts it with a "Strawsonian" account. He alludes to the famous debate regarding the analysis of definite descriptions. On the one hand, according to Russell (1905), every affirmative sentence with a non-denoting definite description as a subject is false. On the other hand, Strawson (1950) argues that such a sentence should be considered neither true nor false. Todd (2016a) argues that the same argument can be restated for sentences which refer to the future. If there is no future, then every sentence of the form "The future features $\phi$ " should be considered false, on the Russellian approach, and indeterminate, on the Strawsonian. The supervaluational proposal of Thomason (1970) might be seen as a Strawsonian account of future contingents, whereas Todd proposes a Russellian alternative.

In their recent paper, Schoubye and Rabern (2017) undermined the parallel between Toddian future tense and Russellian definite descriptions. They argued in particular that the major advantages of the Russellian analysis do not transfer to Todd's proposal (I will refer to some of their major observations in due course). It is therefore questionable whether Todd should rely on the Russellian analysis of the phrase like "The future features $\phi$ " or should he rather simply stipulate (F1) as his intended meaning of the future tense operator. ${ }^{4}$

Setting aside validity of the Russellian justification of Todd's views, I should note that the elegant simplicity of his theory is impressive. In a sense, it is astounding that it had to wait until 2016 to be presented. Well, this is not quite true. I have identified two sources, where a view like (F1) is mentioned. Firstly, it is considered (but instantly discarded) by David Lewis:

It is false that the future holds a sea fight; because 'the future' is a denotationless improper description. (... ) But [if we go this way], our customary thought about 'the' future is in bad trouble. Lewis (1986, p. 207)

A sketch of a theory like (F1) can be also recognized in a few remarks by Tooley (2012):

First of all, there is what might be called 'extreme' presentism, where this is the view that any positive proposition that is expressed by some statement about the past, or about the future, however that statement is interpreted, is false. Tooley (2012, p. 26)

Tooley does not develop this view at any length, only briefly comments:

[E]xtreme presentism with its radical view that all positive propositions about the past (and about the future) are false, has not recommended itself to many philosophers. Tooley (2012, p. 26)

\footnotetext{
${ }^{4} \mathrm{~A}$ few points made in my paper coincide with those presented by Schoubye and Rabern (2017). Especially the line of reasoning outlined in Section 4 is largely parallel to the argument they make in the last section of their paper. There are also many differences in our approach, however, and the two papers constitute independent attacks on Todd's position. Schoubye and Rabern (2017) stress the disanalogy between Russellian definite descriptions and Toddian future contingents, while I accept Todd's theory "as is" and discuss some of its corollaries. I should mention that I was not familiar with Schoubye and Rabern (2017) until recently and the partial coincidence of some of our claims results from similar reaction to parts of Todd's paper rather than from direct influence.
} 
(F1) is not, strictly speaking, a case of extreme presentism in Tooley's sense, as Todd limits his investigation to future tense. Anyhow, it is fair to describe his initial proposal as "extremism". Not only does it partly coincide with Tooley's extreme presentism, but, more importantly, it advocates a quite extreme revision of the future talk of English (it might be what Lewis had in mind, when he warned against "bad trouble").

Russell rightly suggested that "[a] logical theory may be tested by its capacity for dealing with puzzles, and it is a wholesome plan, in thinking about logic, to stock the mind with as many puzzles as possible, since these serve much the same purpose as is served by experiments in physical science". Russell (1905, pp. 484-485). In what follows, I am going to present a list of puzzles that extremism should solve. In my opinion, these "logical experiments" jointly constitute a serious challenge for Todd's theory. I should note that the arguments below undermine extremism only if the theory aims (among other things) at providing an analysis of natural language future tense. In my view, Schoubye and Rabern (2017, pp. 9-10) convincingly argue that it is reasonable to expect that much from Todd's proposal.

To present some of puzzles, I will use a metric version of the tense operator$F_{1}$ - to encode "It will be the case tomorrow". 5 Let us assume then that the future is open (and thus, all $F$-sentences are false) and study how sentences in the future tense behave in various contexts.

1. Assuming (F1), sentences resembling tautologies come out false. Let us take the sentence:

I will have a cup of coffee tomorrow or I won't have a cup of coffee tomorrow. $\left(F_{1} p \vee F_{1} \neg p\right)$

Todd realizes that this kind of cases might be problematic for his proposal. Therefore, he treats them with special care. In the end, he adopts the tactics originally devised by Russell himself and argues that the sentence above may be understood either as $F_{1} p \vee F_{1} \neg p$ or as $F_{1} p \vee \neg F_{1} p$ and observes that, given his semantics, it is a tautology under the second interpretation only (just as the sentence, "The present king of France is bald or not," is a tautology under one of Russellian interpretations only). He continues by noticing that his preferred reading of the sentence above-i.e., $F_{1} p \vee F_{1} \neg p-$ is not a case of the law of excluded middle and it is logically consistent to claim, as he does, that both disjuncts are false. ${ }^{6}$

Nonetheless, this result, even if logically consistent, is still in severe conflict with natural language intuitions, which is a strong argument against extremism. Moreover, an extremist needs to explain why we tend to understand the sentence

\footnotetext{
${ }^{5}$ Or more precisely, "It will be the case exactly 1 unit of time hence." By representing "Tomorrow" as $F_{1}$, I ignore the indexical nature of the term, but it is irrelevant to the examples presented below.

${ }^{6} \mathrm{I}$ should add, and thank the anonymous reviewer for pointing this out to me, that $F_{1} p \vee F_{1} \neg p$ and $F p \vee F \neg p$ may be false in standard tense logic as well, though for different reasons. Under the standard interpretation of $F p$ it is true at $t$ iff $p$ is true at some time later than $t$. Thus, in the extreme case where $t$ is the last moment of time - the end of the world—both $F p$ and $F \neg p$ are false at $t$. In every model where time has no end, however, both $F_{1} p \vee F_{1} \neg p$ and $F p \vee F \neg p$ are always true.
} 
above as a tautology and if he admits that the English "won't" is usually understood as $\neg F$, he needs to accept that all the "won't" sentences of English are usually rendered true by his semantics. Thus, regardless of what we might think, hope, or fear, it is true that Donald Trump won't be impeached and that this paper won't be rejected. If only it would be so easy...

To make things worse, Schoubye and Rabern (2017, pp. 11-12) present a convincing argument that the Toddian "wide scope" reading of "won' $t$ " is intuitively unavailable in natural language (nor can it be rendered salient with explicit disambiguation). Thus, Todd's strategy to explain the impression that the "will or won't" sentences are tautologies is unlikely to succeed. Moreover, it is crucial for Todd that we carefully distinguish $F_{1} \neg p$ from $\neg F_{1} p$ which brings me to the next problem.

2. According to (F1), the English phrase "It won't be the case tomorrow that $\phi$ " is ambiguous. More specifically, there is a syntactic scope ambiguity of the sentences like

(a) I will not drink coffee tomorrow.

It can be understood in either of these two ways:

(b) It will be the case tomorrow that I do not drink coffee. $\left(F_{1} \neg p\right)$

(c) It is not the case that I will drink coffee tomorrow. $\left(\neg F_{1} p\right)$

The ambiguity has severe semantic consequences, as the two senses have radically different truth conditions under (F1). John MacFarlane notices, however, that this kind of semantic ambiguity seems to be missing from the English "will not":

It is striking, though, that although we can mark the syntactic distinction by resorting to cumbersome circumlocutions, as in (b)-(c), these variants seem like different ways of saying the same thing. If you ask somebody who utters (a) whether they meant (b) or (c), you are likely to be met with a blank stare. MacFarlane (2014, p. 216)

Therefore, if MacFarlane is right, the users of English do not recognize the two meanings that Todd is forced to stipulate. It seems, however, that the difference should be easily detectable, given that every sentence of the form $F_{1} \neg \phi$ is false, while every sentence of the form $\neg F_{1} \phi$ is true.

3. Let us reflect for a moment on the temporal operator "It is always going to be the case" $(G)$. It is commonly introduced as a dual of $F(G=\neg F \neg)$. But then, since every sentence of the form $F \phi$ is false, then every sentence of the form $\neg F \phi$ is true. Therefore, (F1) implies that every sentence of the form "It is always going to be the case that $\phi$ " is true.

In a sense, it should not come as a surprise. If $F \phi$ means something like "some moment in the actual future features $\phi$ ", then $G \phi$ means something like "All moments in the actual future feature $\phi$ ". However, since there are no moments in the actual future (because there is no actual future), then the latter claim is vacuously true.

Thus, according to $(F 1)$, it is false that 
I will drink another coffee. $(F p)$

But it is true (surprisingly perhaps) that

I am always going to be drinking coffee. $(G p)$

Also, it is true that

I am always going to be not drinking coffee. $(G \neg p)$

4. (F1) falsifies the basic principle of the majority of tense logics: $\phi \rightarrow H F \phi$. The operator $H$ stands for "It has always been the case that" and the sentence $H \phi$ is true, iff $\phi$ has always been true. Observe that under (F1), even if $\phi$ is true now, the sentence $F \phi$ was once false (assuming that what has in fact happened, might not have happened). Therefore, even if $\phi$ is true, $H F \phi$ is not. According to (F1), it means that, even if I do drink coffee right now, it was false to say that I would. It stands in conflict with how we usually assess our predictions. If you said that I would drink coffee today and I do, then it seems that I am entitled to say that what you said was true (or, more commonly, that you were right). ${ }^{7}$

Also, the principle $\phi \rightarrow H F \phi$, together with its dual $\phi \rightarrow G P \phi$, is meant to grasp an elementary symmetry between temporal concepts. They encode the idea that the present is in the past of the future and in the future of the past. ${ }^{8}(\mathrm{~F} 1)$ violates this idea in at least one direction - the present is no longer in the future of the past.

5. There is a related problem that (F1) generates for analysis of speech acts. Many of them seem to be systematically related with the truth value of the sentences used in the acts. The paradigm example is the act of betting. If $\alpha$ bets that $\phi$, then $\alpha$ wins, only if $\phi$ is true. (For a detailed discussion of speech acts in the context of open future, see Belnap 2002.)

If this understanding of betting is sound, then, given (F1) is accepted, no bet can ever be won. After all, if the future is open, whenever you say "Eclipse will come first", what you say is false (and will remain false forever). Therefore, even if you bet on Eclipse and Eclipse does in fact come first, you still stand no chance, when bargaining with the bookie about your payoff.

A parallel argument might be presented for other speech acts like promise, order, or assertion. Therefore, unless an alternative understanding of speech acts is offered, the future-oriented speech acts are irrational in the context of (F1). Actually, Todd refers (pp. 787-8) to an argument by Arthur Prior to the effect that betting is problematic for an open futurist. He uses this argument to distinguish his version of open futurism from Prior's. However, he does not restate this

\footnotetext{
${ }^{7}$ Observe that some semantics which Todd would qualify as open futurist are not threatened by this problem. For example, Thomason's supervaluationism makes every future contingent neither true nor false, but it simultaneously validates $\phi \rightarrow H F \phi$. For a thorough discussion of the so-called retrospective accuracy assessment of assertions, see MacFarlane (2014, ch. 9).

${ }^{8}$ In relational semantics, these two sentences hold true, if the accessibility relation for operator $F$ is the converse of the relation for operator $P$.
} 
argument against his own proposal, nor does he make any attempt to rationalize betting behavior within his account of the future tense. ${ }^{9}$

6. Let us introduce one more connective, "it is determined that" $(D)$ expressing causal necessity. We say that $D \phi$ is true, iff $\phi$ is true in all causally possible futures. Remember that even if $D \phi$ is true, the future might still be open. It is enough that some other aspect of the future is undetermined.

Then, if the future is open, (F1) breaks the natural connection of "will" $(F)$ and "determined" $(D)$. For example, even if $\phi$ is causally necessary to happen, it is still false that it will happen. So, the following implication is false:

If it is determined that I will drink a cup of coffee tomorrow, then I will. $(D p \rightarrow F p)$

7. Every (material) implication with an antecedent in the future tense is true. Therefore, it is true that:

- If I drink a cup of coffee tomorrow, then I will be the king of France. $(F p \rightarrow F q)$

8. Since all sentences in future tense are false, then "I will drink a cup of coffee tomorrow" and "I will not drink a cup of coffee tomorrow" are both false. Todd is well aware of that and he is ready to accept it. However, he might have not noticed that it means that these two are (materially) equivalent. Thus, if the future is open, then it is also true that:

I will drink a cup of coffee tomorrow, if and only if I will not. $\left(F_{1} p \leftrightarrow F_{1} \neg p\right)$

Perhaps none of the arguments above is decisive. However, when accumulated, they constitute a rather strong case against (F1) as a semantics of future tense. This result might serve as a warning to take cum grano salis the slogans like "there is no (actual) future."

To my mind, a proponent of (F1) has two solutions open to him. He might bite the bullet, endorse the error theory, and insist that people are massively confused when they use future tense. This strategy has not recommended itself to many philosophers indeed. Even Todd admits that "[t]his is not an easy philosophical road to walk" (p. 796). This is not to say that a philosopher has nothing to say about the most fortunate semantics of future tense. It might be that our ordinary attitude towards "the future" is tangled and a philosopher can help to clarify, or even regiment, our way of talking. However, when a philosophical theory (and a semantic theory in particular) gets as remote from common usage as (F1) does, then the concept of the future encoded by this theory is probably very distantly related to our everyday notions. It leaves us with the other solution, which is to admit that (F1) models a technical sense of "will" used for example by extreme presentists. Then, (F1) might be useful, if the purpose

\footnotetext{
${ }^{9}$ Schoubye and Rabern (2017, pp. 13-15) provide a different argument that many propositional attitudes such as " $x$ believes that" or " $x$ fears that" are at odds with the Russellian analysis of future tense.
} 
was to study the linguistic niche of these philosophers. However, it will not teach us much about how people actually do, or should, think about notions like "the future".

None of these two solutions seems particularly appealing and both might discourage one from endorsing (F1) (they certainly discourage me). However, I still believe that any of these two solutions are better than the route that Patrick Todd actually chose.

\section{From Extremism to Austerity}

In face of the mounting technical difficulties, Todd has relaxed his view. ${ }^{10}$ He gave up some of his philosophical chastity and acknowledged that some sentences about the future should be true, even if there is no future. Specifically, he makes an exception for sentences that talk about the future events which are causally determined to happen. For example, he admits that the sentence like "I will die" is true. To convey this insight technically, the author proposes a modification of the definition of the future tense $(\mathrm{F} 2)$ :

It will be the case that $p$ iff there exists a unique actual future, and that future features $p$, OR $p$ is true in all causally possible futures. (Todd 2016a, p. 792) ${ }^{11}$

Since all causally possible futures feature my death, the sentence "I will die" is true. Thus, the semantic maneuver allows the author to generate the result he desired. The semantic shift marks a transition from extreme to austere form of semantics, to use Tooley (2012) terms once again. In the austere version of presentism, we can reasonably talk about the future as long as it is in some sense present, for example, if it is "present in its causes".

I understand the "linguistic" motivation to escape from the dubious theory (F1); however, the fix proposed by Todd reduces rather than increases the philosophical allure of his position. To be fair, (F2) does avoid a few of the worries pointed out above. To be exact, the problems 3 and 6 do not threaten this position. However, the remaining problems are not answered by this semantic modification (these problems apply to any $p$ that is not causally determined to happen). Worse even, the transition from $(\mathrm{F} 1)$ to $(\mathrm{F} 2)$ generates new semantic oddities. For example:

9. If it is causally determined that I will have one more cup of coffee today, but it was not causally determined two hours ago (e.g., I could have taken a nap an hour ago), then it is true to say:

I will drink a cup of coffee today but an hour ago it was false that I would. $(F p \wedge P \neg F p)$

\footnotetext{
${ }^{10}$ I am not sure of which of the problems I have described above Todd was aware. In his paper, he writes (pp. 791-2) that he was particularly discouraged by the result that I described in point 6.

${ }^{11}$ A very similar, disjunctive definition of the future tense operator had previously been proposed by a couple of authors who assume that indeterminism is compatible with existence of the actual future (see Malpass and Wawer 2012, p. 132). The argument I present in the next section does not apply to their view.
} 
To be fair, Todd does not find this sentence as peculiar as I do. He even tries to justify why we should consider it true in a recent paper (Todd 2016b).

10. Whenever it is determined that I will have either a cup of coffee or a cup of tea, but it is undetermined which one, I can truly utter the sentence which sounds, to my ear, very much like a contradiction:

I will drink coffee or tea, but it is not the case that I will drink coffee or that I will drink tea. $(F(p \vee q) \wedge \neg(F p \vee F q))$

11. The next problem with (F2) is that nothing is ever true in this theory without being causally determined. It means that it is never true that:

It is not determined that John will drink another coffee today but he will. $(\neg D p \wedge F p)$

It is a matter of some controversy, whether these kind of sentences should ever be considered true (see MacFarlane 2014, pp. 215-216). However, it is worth noticing that they always come out false in (F2). (In fact, they come out false also in (F1), but for different reasons.)

On top of all of those, there is a methodological problem with (F2). Namely, the second disjunct in the definition of will which mentions causally possible futures seems to be added entirely ad hoc, just to explain away some controversial consequences.

I hope that by now it is clear that the switch from (F1) to (F2) is not as good a deal as it might seem. ${ }^{12}$ We do get rid of two controversial cases, but we generate two new ones. Even if this new semantics is slightly better, it is not much better than the previous one. Thus, the meta-philosophical reasons that might discourage us from accepting (F1) apply to (F2) as well. Things, however, get even worse...

\section{Back to Peirceanism}

Remember that Todd have accepted (OF), which says that if the future is open, then there is no actual future. Bearing this in mind, let us muse over the modified truth condition of the future tense operator:

$F \phi$ is true iff there exists a unique actual future, and that future features $\phi$, OR $\phi$ is true in all causally possible futures.

I shall encode this condition symbolically:

$F \phi$ iff $(@ F \phi$ or $D \phi)$

Let us now consider two scenarios. First, assume that the future is open. It implies that there is no actual future. It implies in turn that the first disjunct in the definition

\footnotetext{
${ }^{12}$ It definitely seemed a good deal to Todd, who writes "I am deeply grateful to Andrew Bailey for suggesting this disjunctive approach, thereby saving me from a great many complications." Todd (2016a, p. 792 , n. 28)
} 
above is false and $F \phi$ inherits the truth value of the second disjunct. Thus, if the future is open, we arrive at a simplified definition of truth:

$F \phi$ iff $D \phi$

Now, let us assume that the future is not open. Then, there is only one possible way in which the world can develop. Todd admits that in this case, the actual future does exist and it is identical to the unique causally possible future (see p. 785). But then, doubtlessly, whatever the actual future features is determined to happen. Thus, in case the future is not open, we arrive at the same simplified definition:

$F \phi$ iff $D \phi$

Therefore, no matter if the future is closed or open, the truth conditions for the future tense operator are exactly the same. The first disjunct in definition (F2) makes no difference and $F \phi$ and $D \phi$ are equivalent. The equivalence can be derived on the basis of (OF) and (F2) alone; so, provided they are necessary, the equivalence of $F \phi$ and $D \phi$ is also necessary. Moreover, if we assume that (OF) is not merely a metaphysical hypothesis, but it serves to partly explicate the meaning of "open," "future," and "actual," then equivalence of $F \phi$ and $D \phi$ becomes an analytic truth.

We can put the argument differently, if we notice that on the open future view, the following implication holds: $\neg D \phi \rightarrow \neg @ F \phi$. It says that if $\phi$ is not determined to happen, then the actual future does not feature $\phi$. Todd admits that much when he says that "given indeterminism, there doesn't now exist a complete 'story of the future."” (Todd 2016a, p. 776). But then, we can reason as follows:

$$
\begin{array}{cl}
\begin{array}{c}
F \phi \leftrightarrow(@ F \phi \vee D \phi) \\
\neg D \phi \rightarrow \neg @ F \phi
\end{array} & \text { (definition of 'will' in F2) } \\
F \phi \text { iff } D \phi & \text { (the stipulated meaning of OF) }
\end{array}
$$

Thus, it is clear that the first disjunct is just a smokescreen. It is redundant for any open futurist in the style of Todd. Classical logic and Todd's assumptions are sufficient to establish equivalence of "will" and "determined."

However, if we identify these two, we simply end up with the good old Peircean semantics of Arthur Prior (see Prior 1967, chapter 7). Of course, it is not a sin to adopt (even unconsciously) a semantics devised by such an illustrious philosopher. ${ }^{13}$ Todd's major problem is not that the semantics he devised is not entirely novel, but that he himself wants to distinguish his view from Priorian Peirceanism:

Hartshorne and Prior showed that one could have an open future without denying bivalence, given (at least what most will regard as) a rigged, causally-loaded semantics for the future-tense 'will', according to which to say that something will happen is (roughly) to say that it is determined to happen. However, I aim to

\footnotetext{
${ }^{13}$ One just needs to bear in mind that most of the problems mentioned in this paper apply, mutatis mutandis, to the Peircean semantics of Prior. It might be a reason why the semantics has not been widely popular among philosophers (or computer scientists; see Gabbay et al. 1994, pp. 5-6). The only defense of Peirceanism as a semantics of English "will" that I am aware of has been raised in an unpublished paper by Rhoda (2006).
} 
show that one can have such an open future without adopting these semantics.

Todd (2016a, p. 777)

Given the argument above, Todd fails to fulfill his promise. Doubtless, his initial proposal (F1) does achieve his aim. It does distinguish "plain" future tense from "causally-loaded" future tense. In Todd's initial proposal, the sentence "I will die" is false, while it is true in Peirceanism. However, Todd decided to give up (F1) as an analysis of "will" and accept another semantics-(F2) - that he finds less problematic. Closely examined, however, (F2) turns out to be nothing but Prior's Peirceanism. $^{14}$

Ultimately, the author has sacrificed the novelty of his proposal for the sake of a slightly more intuitive explanation of a few controversial cases. At the same token, he failed to achieve his primary aim, which was to propose a semantics which would (a) render all future contingents false and (b) distinguish "plain" future tense from "causally-loaded" future tense. Therefore, I would suggest Todd to reject the tradeoffs and stick to (F1). In fact, I believe that he could philosophically support the result that scared him away from (F1). After all, if there is no actual future, the actual future does not feature my death, so the full-fledged Russellian open futurist in the style of Todd can easily explain why it is false that I will die.

\section{Summary}

I have argued that none of the semantics of "will" recently proposed by Patrick Todd is a reasonable analysis of the English future tense. Moreover, I claim that the proposal he ultimately recommends, on closer inspection, turns out to be a version of the semantics which he wants to reject. In light of these results, it would be better to either abandon his semantic project altogether, or stick to his initial proposal, as it might be useful for some theoretical applications in philosophy of time.

Notably, Todd's semantic theories (especially the first one) are guided by, and faithful to, the view that there is no actual future. Therefore, the failure of his semantic project might be seen as an indirect argument against the metaphysical thesis motivating his project.

Funding Information The research was funded by the National Science Center, Poland (project No. 2016/23/B/HS1/00464).

\section{Compliance with Ethical Standards}

Conflict of Interest The author declares that he has no conflict of interest.

\footnotetext{
${ }^{14}$ As I already mentioned, a very similar conclusion is derived by Schoubye and Rabern who write that "The problem is that now the quasi-Russellian analysis is nothing but an idle wheel. (...) On the assumption that there is never a unique actual future, Todd's semantics is logically and truth-conditionally equivalent to the Peircean semantics.” Schoubye and Rabern (2017, p. 17)
} 
Open Access This article is distributed under the terms of the Creative Commons Attribution 4.0 International License (http://creativecommons.org/licenses/by/4.0/), which permits unrestricted use, distribution, and reproduction in any medium, provided you give appropriate credit to the original author(s) and the source, provide a link to the Creative Commons license, and indicate if changes were made.

\section{References}

Belnap, N. (2002). Double time references: speech-act reports as modalities in an indeterminist setting. In Wolter, F., Wansing, H., de Rijke, M., Zakharyaschev, M. (Eds.) Advances in modal logic, (Vol. 3 pp. 37-58). Singapore: World Scientific Publishing Co.Pte.Ltd.

Belnap, N., Perloff, M., Xu, M. (2001). Facing the future: agents and choices in our indeterministic world. New York: Oxford University Press.

Gabbay, D., Hodkinson, I., Reynolds, M., Finger, M. (1994). Temporal logic: mathematical foundations and computational aspects, vol. 1 of Oxford logic guides. Clarendon Press.

King, J.C. (2003). Tense, modality, and semantic values. Philosophical Perspectives, 17(1), 195-246.

Leśniewski, S. (1992). Is all truth only true eternally or is it also true without a beginning. In Surma, S., Strzednicki, J., Barnett, D. (Eds.) Collected works, (pp. 114-126): Kluwer Academic Publisher and Polish Scientific Publishers.

Lewis, D. (1986). On the plurality of worlds. Oxford: Blackwell Publishers.

MacFarlane, J. (2014). Assessment sensitivity: relative truth and its applications. Oxford: Clarendon Press.

Malpass, A., \& Wawer, J. (2012). A future for the thin red line. Synthese, 188(1), 117-142.

Markosian, N. (2004). A defence of presentism. In Zimmerman, D.W. (Ed.) Oxford studies in metaphysics, (Vol. 1 pp. 47-82). Wotton-under-Edge: Oxford University Press.

Øhrstrøm, P. (1984). Anselm, Ockham and Leibniz on divine foreknowledge and human freedom. Erkenntnis, 21, 209-222.

Øhrstrøm, P., \& Hasle, P.F.V. (1995). Temporal logic: from ancient ideas to artificial intelligence. Kluwer Academic Publishers.

Prior, A. (1967). Past, present and future. Clarendon Press. References to the 1978 reprint.

Rescher, N. (1968). Truth and necessity in temporal perspective. In Gale, R.M. (Ed.) The philosophy of time: a collection of essays (pp. 183-220). London: Macmillan Press Ltd.

Rhoda, A. (2006). In defense of Prior's 'Peircean' tense logic. Avalable at: http://www.alanrhoda.net/ papers/In_Defense_of_Prior's_Peircean_Tense_Logic.pdf, accessed: Oct, 11, 2017.

Russell, B. (1905). On denoting. Mind, 14(56), 479-493.

Schoubye, A.J., \& Rabern, B. (2017). Against the Russellian open future. Mind. Forthcoming, preprint available at www.schoubye.org/papers/RTT.pdf, access Sep. 22, 2017.

Strawson, P.F. (1950). On referring. Mind, 59(235), 320-344.

Thomason, R.H. (1970). Indeterminist time and truth-value gaps. Theoria, 36, 264-281.

Todd, P. (2016a). Future contingents are all false! On behalf of a Russellian open future. Mind, 125(499), 775-798.

Todd, P. (2016b). On behalf of a mutable future. Synthese, 193(7), 2077-2095.

Tooley, M. (1997). Time, tense, and causation. Oxford: Clarendon Press, Oxford.

Tooley, M. (2012). Against presentism: two very different types of objection. In Bardon, A. (Ed.) The future of the philosophy of time (pp. 25-40). Abingdon: Routledge. 